\title{
ESPELHOS DA EXISTÊNCIA: REVERBERAÇÕES FILOSÓFICAS EM ANTONIO LOBO ANTUNES E CECÍLIA MEIRELES
}

Francisca Marciely Alves Dantas ${ }^{1}$

RESUMO: O presente artigo tem por objetivo delinear um estudo comparativo nas tessituras poéticas de Antonio Lobo Antunes e Cecília Meireles, buscando tecer reflexões filosóficas acerca da percepção do efêmero na crônica "A velhice" (2000) e no poema "Retrato" (1939) dos respectivos autores, explicitando personagens que se encontram perplexos diante das imagens de si mesmos refletidas no espelho, o que possibilita um exame de consciência da própria existência.

PALAVRAS-CHAVES: Literatura Comparada; Antonio Lobo Antunes; Cecília Meireles;

\section{MIRRORS OF EXISTENCE: REVERBERATIONS PHILOSOPHICAL IN ANTONIO LOBO ANTUNES AND CECÍLIA MEIRELES}

ABSTRACT: This article aims to outline a comparative study in poetic weavings of Antonio Lobo Antunes and Cecilia Meireles, seeking to weave philosophical reflections on perception of chronic ephemeral in the chronicle "A velhice" (2000) and the poem "Retrato" (1939) of the respective authors, describing characters we are perplexed by the images of themselves reflected in the mirror, which allows for an examination of conscience of its own existence.

KEYWORDS: Comparative Literature; Antonio Lobo Antunes; Cecilia Meireles.

O homem não deve poder ver a sua própria cara.

Isso é o que bá de mais terrivel. A Natureza deu-lhe o dom de não a poder ver, assim como de não poder fitar

os seus próprios olbos.

Só na água dos rios e dos lagos ele podia fitar seu rosto. E a postura, mesmo, que tinha de tomar, era simbólica. Tinba de se curvar, de se baixar para cometer a ignominia de se ver.

O criador do espelho envenenou a alma humana.

(Bernardo Soares) $)^{2}$

\footnotetext{
${ }^{1}$ Mestranda em Letras pela UFPI na área de Estudos Literários.

2 SOARES, Bernardo (um dos heterônimos de Fernando Pessoa). In: PESSOA, 1986, p. 208.
} 
Refletir acerca da Literatura no sentido de que é uma instância poética que transporta o leitor a um universo ficcional artístico adquire sentido a partir da ideia de que a escrita literária é permeada de vivências de outros mundos, que dialogam de maneira profícua e se materializam na linguagem desconstruída do fenômeno literário. A confluência de diferentes saberes e culturas, seja em épocas distintas ou associadas a um mesmo marco temporal, faz com que a discussão literária sobreviva a um constante confronto e a elaboração de novos posicionamentos estéticos e culturais.

Nesse sentido, o objetivo desse estudo é analisar os pontos de intersecção e convergências na escrita literária de dois autores contemporâneos entre si, contudo de nacionalidades distintas, traçando, dessa forma, um diálogo luso-brasileiro de suas respectivas literaturas. Deflagrados em uma época de grande desenvolvimento literário e inversão de valores humanísticos figurarão em cena os escritores Antonio Lobo Antunes e Cecília Meireles, buscando apontamentos subjetivos semelhantes e distintos em suas escrituras, iluminando a essência poética singular a cada um deles.

Desse modo, elaborar uma análise comparativa que aproxime os autores em questão justifica-se pelo fato de ambos tratarem com simplicidade e labor poético temas que revelam a condição humana e suas contradições, abrindo caminhos para explorações filosóficas acerca da experiência da passagem do tempo, o que constitui a chave elucidativa do estudo aqui delineado. Desse modo, Nitrini elucida em Literatura Comparada que:

A linguagem poética surge como um diálogo de textos. Toda sequência está duplamente orientada: para o ato da reminiscência (evocação de uma outra escrita) e para o ato de somação (a transformação dessa escritura). O livro remete a outros livros e, pelo processo de somação, confere a esses livros um novo modo de ser, elaborando assim a sua própria significação (NITRINI, 1997, p. 162).

Tendo em vista que a narrativa contemporânea torna-se pano de fundo para a expressão do novo homem que se configura em pleno século XXI, a aparição de temas que permeiam a existência humana e seus anseios é acolhida na linguagem literária de maneira reflexiva. Essa acepção pode ser mais bem compreendida em Fadul:

A angústia, a solidão, o medo e o sofrimento estão presentes, com frequência, na temática contemporânea não somente para expressar a perplexidade e fragilidade do homem, diante da falência de antigos valores, mas também como um modo de 


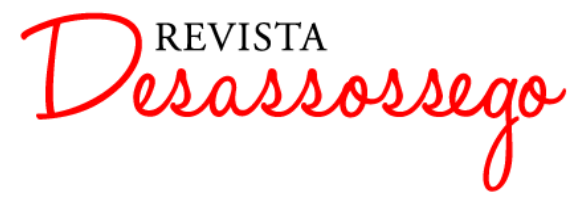

DESASSOSSEGO 12 | DEZ/2014 | ISSN 2175-3180

DOI: http://dx.doi.org/10.11606/issn.2175-3180.v6i12p46-53

intensificar as situações de conflito, a ambiguidade diegética e os muitos ângulos da verdade (FADUL, 1997, p. 61).

Nesse sentido, ao se propor um exercício crítico-comparativo que irá trazer à superfície questionamentos acerca da efemeridade da vida e o trânsito do homem mediado pelo tempo torna-se imprescindível uma associação com textos de base filosófica à materialidade literária, delineando, dessa forma, um estudo interdisciplinar. Assim, é preciso entender que "para se fazer interdisciplinaridade, não basta tomar um 'assunto' e convocar em torno duas ou três ciências. A interdisciplinaridade consiste em criar um objeto novo que não pertença a ninguém. O Texto é, creio eu, um desses objetos” (BARTES, 1988, p. 99). Para tanto, uma apreciação crítica dessa natureza interessa-se em buscar o equilíbrio entre os aspectos teóricos filosóficos manifesto no texto literário e as peculiaridades que o singularizam.

Amparado sob esse constante diálogo entre Literatura e Filosofia, o construto simbólico literário recria as experiências e as situações-limite vivenciadas pelo indivíduo, materializadas no plano imaginário da obra e acaba por possibilitar o surgimento de novas paisagens inteligíveis do conhecimento humano, fazendo da narrativa literária uma instância poética que propicia a reflexão de aspectos intrínsecos à existência do homem.

Sendo assim, o convite para um encontro entre Cecília Meireles e Antonio Lobo Antunes é extremamente plausível, uma vez que o poema "Retrato", publicado em 1939, dialoga de uma maneira muito lúcida com a crônica "A velhice", publicada em 2002, dos respectivos autores. Ambos os textos retratam a tomada de consciência do homem diante do tempo que passou, percebidos por meio da imagem fixa dos personagens frente ao espelho.

Espelho esse que revela as marcas de um tempo presente e faz pensar no passado que não volta mais, num dado instante epifânico quando os olhos se abrem e os sujeitos líricos percebem a verdade que está diante dos seus olhos, mas somente nesse exato momento se dão conta. A partir disso, os personagens constroem imagens existenciais de si mesmos, por meio do confronto imagético diante do espelho. Assumindo posições narcisistas, os sujeitos líricos acabam caindo no âmago de si mesmos, causando um embate subjetivo de si para si.

O poema "Retrato" (1939) de Cecília Meireles inicia-se com a percepção temporal do sujeito lírico diante do espelho. 
Eu não tinha este rosto de hoje, assim calmo, assim triste, assim magro, nem estes olhos tão vazios, nem o lábio amargo.

Eu não tinha estas mãos sem força, tão paradas e frias e mortas; eu não tinha este coração que nem se mostra. Eu não dei por esta mudança, tão simples, tão certa, tão fácil:

- Em que espelho ficou perdida a minha face?

(MEIRELES, 1939, p. 21)

O próprio título do poema sugere um estado estático, a palavra "retrato" constitui uma forma de lembrar-se de determinada situação, que remete a algo que já aconteceu. Escrito em primeira pessoa, o sujeito lírico se olha e não reconhece o rosto refletido, o que lhe causa certa estranheza. No primeiro verso percebe-se que há referência ao "hoje" em contraponto com o estado de negação, advindo da sequência de palavras negativas e adjetivos que caracterizam o sujeito lírico de maneira angustiante, engendrando um descompasso interno entre a imagem refletida e o tempo presente.

Por outro lado, se pensarmos na crônica "A velhice" (2002), de Antonio Lobo Antunes, percebe-se a mesma sensação do eu-lírico do poema citado: a consciência do transitório, dos tempos já vividos, a partir da imagem refletida no espelho. Escrito em primeira pessoa, a crônica do autor descreve as impressões do personagem frente ao passar dos anos.

Devo estar a ficar velho: as Paulas Cristinas têm mais de 20 anos, os Brunos Miguéis já vão nos 15, as Kátias e as Sónias deram lugar a Martas, Catarinas, Marianas. A maior parte dos polícias são mais velhos do que eu. Comecei a gostar de sopa de Nabiças. A apetecer-me voltar mais cedo para casa. A observar, no espelho matinal, desabamentos, rugas imprevistas, a boca entre parêntesis cada vez mais fundos. A ver os meus retratos de criança como se fosse um estranho (ANTUNES, 2002, p. 45).

Apesar de parecer uma cena prosaica e corriqueira, o olhar-se diante do espelho é compreendido em ambos os textos não como uma cena comum, mas como um 
acontecimento enigmático e revelador simultaneamente. Enigmático no sentido de que ao perceber a imagem de si mesmo no espelho, os personagens vislumbram uma certeza irrefutável: a efemeridade da vida, ao mesmo tempo em que dar-se conta disso revela um desconforto. Desconforto provocado pelos sinais de envelhecimento que o corpo manifesta e que engendra interrogações acerca do que passou. As cicatrizes ${ }^{3}$ marcadas no corpo: rosto calmo, triste, magro, rugas imprevistas, lábio amargo, boca entre parênteses citadas nos textos indicam a passagem do tempo, marcam a velhice, o fim da vida. Sob esse prisma, nos deparamos com dois personagens perplexos com a experiência desse olhar perscrutador.

A representação do antes e depois são expressas pelas palavras "retrato" e "velhice" que intitulam os textos dos autores, que em uma concepção dialética sugerem a ideia de um movimento temporal. Movimento esse que "assegura a manutenção das mesmas coisas através da sua repetição e do seu contínuo retorno" (AGAMBEM, 2005, p. 113). As reflexões desencadeadas a partir da imagem no espelho provocam um retorno ao passado, ao mesmo tempo em que parece elucidar o instante-já.

As vivências de cada indivíduo no tempo presente não são postas em questão de modo visível, como um registro em um diário, pois "a mente humana tem a experiência do tempo mas não a sua representação, ela necessariamente concebe o tempo por intermédio de imagens espaciais" (AGAMBEN, 2005, p.112). O espelho adquire aqui o símbolo da revelação, demonstrando paisagens da existência em conflito, ou seja, há a presença e ausência simultaneamente do "eu", transpondo o indivíduo ao centro de suas motivações humanas, seu verdadeiro ser. Reforçando o poder simbólico do espelho, esse funciona como um campo recíproco de consciências, suscitando reflexões sobre o enigma da condição humana.

As imagens existenciais construídas pelos personagens transcendem o "eu" e alcançam um estágio latente de consciência. $\mathrm{O}$ reflexo do espelho desponta muito mais do que se pode ver, revela o indizível da consciência dos sujeitos líricos. Afinal, estão ali frente a frente, delimitando um "eu" que especula acerca da própria existência. No entanto, ambos assumem posições distintas diante da percepção da fugacidade do tempo.

Apoiados em si mesmos e diante da fragilidade que toca o ser frente ao descompasso do tempo, os personagens estão cada um seu espaço consciencioso, seguros

\footnotetext{
3 A palavra "cicatrizes" pode ser aqui associada ao texto clássico pagão $A$ cicatriz de Ulisses, uma vez que a partir da marca percebida no corpo de Ulisses faz se um regresso no tempo, com o intuito de esclarecer o motivo da cicatriz em seu corpo.
} 
da concepção transitória da vida: "tão certa, tão simples, tão fácil" (MEIRELES, 1939, p. 21). No poema de Cecília Meireles aflora um eu-lírico imbuído de questões acerca de si mesmo, deixando transparecer uma angústia, sentida como uma morte simbólica, a ponto de está "morrendo em vida".

Entendendo que a existência é um contínuo nascer e morrer, Cecília Meireles traz à luz um sujeito que se vê em fragmentos, em pedaços diante do espelho, recolhendo aquilo que permaneceu: mãos sem força, paradas, frias e mortas. A não recuperação de um estado visivelmente afortunado faz com o "eu" que resvala no poema sinta-se internamente abalado, guardando um coração que insiste em não querer ser mostrado, uma vez que não há júbilo dentro de si, apenas o receio de aproximação com a morte.

Ao trazer à análise comparativa o personagem que deslinda na crônica de Antonio Lobo Antunes intuímos que não há nenhum receio e nem medo diante do transitório, apena o conformismo autêntico e feliz diante da passagem da vida e das marcas de envelhecimento.

Quando der por mim, encontro o meu sorriso na mesinha de cabeceira, a troçar-me, num copo de água, com 32 dentes de plástico. Reconhecerei o meu lugar à mesa pelos frasquinhos dos medicamentos sobre a toalha, que me farão lembrar as bandeiras que os exploradores antigos, vestidos de urso como os automobilistas dos tempos heroicos, cravavam nos gelos polares. [...] Devo estar a ficar velho.

E no entanto, sem que me dê conta, ainda me acontece apalpar a algibeira à procura da fisga. Ainda gostava de ter um canivete de madrepérola com sete lâminas, saca-rolhas, tesoura, abre-latas e chave de parafusos. Ainda queria que o meu pai me comprasse na feira de Nelas, um espelhinho com a fotografia da Yvonne de Carlo, em fato de banho, do outro lado. Ainda tenho vontade de escrever o meu nome depois de embaciar o vidro com o hálito (ANTUNES, 2008, p.45).

Observamos na crônica do autor português um eu-lírico em paz consigo mesmo, sem revolta, amparado por aquilo que exatamente completa seu estado de júbilo: o cotidiano pleno. E apesar da velhice, o personagem ainda manifesta lucidez para encontrar contentamento nos detalhes que são agregados à sua idade, ou seja, o reconhecimento do tempo fugaz não o motiva a pensar no fim da vida, mas compreender que há ainda muito para se viver e se reinventar como ser autêntico no mundo. 
A velhice constitui aqui um mote para se pensar nas escolhas eleitas ao longo do percurso existencial, uma vez que cada estágio da vida traz-lhe questionamentos devidos, ao passo que as respostas surgem à medida que há interrogações em torno do já vivido. A respeito disso, Ricour explica em Tempo e Narrativa (1997, p.45) que "a interrogação tornase mais premente quando o ser afetado se torna afecção de si mesmo: o tempo é aí, com efeito, implicado de modo mais radical".

O poema "Retrato" (1939) finaliza-se com uma interrogação do eu-lírico a respeito de sua própria existência: "Em que espelho ficou perdida a minha face? (MEIRELES, 1939, p. 21). Já a crônica “A velhice” (2002) arremata com um tom reflexivo a narrativa poética, expressando um repensar do eu-lírico em torno de si mesmo: "Pensando bem (e digo isto ao espelho), não sou um senhor de idade que conservou o coração de menino. Sou um menino cujo envelope se gastou (ANTUNES, 2008, p. 45). E porque não falar na exuberância poética assinalada nessas literaturas tão singulares, o essencial que permeia o existir dito em tão poucas palavras, entorpecidas de perscrutações profundas. Para tanto, a poesia que emana de tais escritos possui a função de "revelar a condição paradoxal do homem" (PAZ, 1982, p. 189).

Em ambos os textos há o extravasamento da consciência diante do tempo. O confronto existencial, condensado a partir da percepção do transitório, causa no indivíduo estranhamento e conflito causando interrogações que o lançam ao embate de si por si mesmo, num aparente conflito entre aparência e essência, proclamado na poeticidade permitida nos textos literários de ambos os autores e suscitado pelos reflexos das imagens dos personagens no espelho.

Tema tão comum à Literatura e à Filosofia, a responsabilidade do homem diante de suas escolhas contempla um estágio autêntico do viver humano, desvendando a condição plena do existir. No poema "Retrato" (1939) visualizamos uma persona com um coração que nem se mostra, envolto em uma existência angustiante. Entretanto, a crônica "A velhice" (2002) apresenta um senhor de idade com um coração de menino, imerso em um cenário de plenitude. Temos, então, duas possibilidades distintas diante do olhar-se no espelho, uma escolha eleita a cada um dos personagens, ou seja, cada um seguiu seu próprio compasso diante da facticidade ${ }^{4}$ a que são colocados à prova.

O sentido da vida autêntica está conectado a três pilares: tempo, escolhas e liberdade. A partir do momento que o homem compreende que viver não significa

\footnotetext{
4 A facticidade é o coeficiente da adversidade das coisas, ou seja, os extravios, embaraços, obstáculos.
} 
necessariamente caminhar para a morte, mas perceber no efêmero algo que vai além de uma simples passagem contingencial do tempo, ele elege escolhas autênticas. Dessa forma, exerce a condição de ser livre, uma vez que "o próprio da realidade humana é ser sem desculpa” (SARTRE, 2008, p.679), sou responsável por mim mesmo enquanto maneira de ser e tenho consciência das escolhas e das consequências advindas destas.

Analisando por esse ângulo, o instante que se vive é o que já foi vivido, num piscar de olhos somos arrastados pelo tempo. Na ilusão de tentar demarcar os momentos em passado-presente-futuro é que o homem se insere num campo de tensão consciencioso. Culpar o "tempo" parece ter se tornado lugar-comum no viver entre as gentes, contudo "para a realidade humana ser é escolher-se" (SARTRE, 2008, p. 545). Experimentar o tempo em sua medida fugaz permite ao homem conceber uma postura autêntica diante de si mesmo.

A relação acurada que se faz entre a imagem dos personagens no espelho e a consciência humana elucida o que podemos chamar de "alma minha", ou seja, o espelho apenas devolve "a imagem do que somos" (SARTRE, 2008, p. 57). Nessa perspectiva, a paisagem existencial dos sujeitos líricos desdobrada poeticamente nos textos evoca não somente aspectos físicos, mas também aspectos intrínsecos à existência, ao fragmentário humano. É o tempo circunscrito no corpo e na consciência humana.

\section{BIBLIOGRAFIA}

ANTUNES, Antonio Lobo. Livro de Crônicas. Lisboa: Publicações Dom Quixote, 2008. AGAMBEN, Giorgio. Infância e história: destruição e origem da história. Belo Horizonte: UFMG, 2005.

BARTHES, Roland. Jovens pesquisadores. In. O rumor da língua. São Paulo: Brasiliense, 1988.

FLORY, Suely Fadul Villibor. O Leitor e o labirinto. São Paulo: Arte e Ciência, 1997.

MEIRELES, Cecília. Viagem: poesia - 1929-1937. Lisboa: Império, 1939.

RICOEUR, Paul. Tempo e narrativa. Tomo III. Tradução de Roberto Leal Ferreira. São Paulo/Campinas: Papirus, 1997.

PAZ, Octávio. O arco e a lira. Rio de Janeiro: Nova Fronteira, 1982.

SARTRE, Jean Paul. O Ser e o nada. Ensaio de Ontologia Fenomenológica. Tradução de Paulo Perdigão. Petrópolis: Vozes, 2008.

Jean Paul. O Existencialismo é um humanismo. Tradução e notas de Vergílio Ferreira.

Lisboa: Editorial Presença, 1970. 